\title{
Arterial Concentration and Forearm Extraction of Glucose and Insulin during the Early Phase of a Glucose Infusion*
}

\author{
G. Riccardi, D. Heaf, L. Kaijser, B. Eklund and L. A. Carlson \\ King Gustaf V Research Institute and the Departments of Internal Medicine and Clinical Physiology, \\ Karolinska Hospital, Stockholm, Sweden
}

Summary. The concentrations of glucose and insulin were determined with high precision at half minute intervals in arterial and deep forearm vein blood after a bolus injection of glucose $(4 \mathrm{~g})$, followed by a constant $i$. v. infusion $(200 \mathrm{mg} / \mathrm{min})$, in four healthy subjects. The values for the deep vein were corrected for the transit time, which was determined by injection of Cardio-green. Arterial glucose peaked at the end of the bolus injection, venous glucose $1^{1 / 2}$ min later. Arterial insulin reached its maximum later than glucose, after $2^{1 / 2}-4 \mathrm{~min}$. The venous insulin reached its maximum later and was much lower than the arterial level, in two cases only around $50 \%$ of the arterial concentration. It is concluded that early after glucose administration there is a considerable extraction of both glucose and insulin by the forearm. Since the insulin extraction was quite variable venous insulin concentrations cannot be used for the assessment of early insulin response to glucose.

Key words: Arterial insulin, venous insulin, arterial glucose, venous glucose, human, forearm, muscle, early response, glucose infusion.

In the last 15 years the early phase of the glucose induced insulin secretion has been studied by many groups under various conditions [1-7] in order to understand the pathogenesis of diabetes mellitus and to define the prediabetic state in which the early insulin response is abnormal $[2,7]$. The early plasma insulin response to glucose has, however, only been described for venous blood and not for systemic arterial

\footnotetext{
* Supported by the Swedish Medical Research Council $(19 X-204)$
}

blood. The insulin concentration in venous blood is determined not only by the insulin release from the pancreas but also by insulin extraction in tissues drained by the venous blood. Thus a low insulin concentration in venous blood in response to a glucose challenge may theoretically be due to either a low secretion or to an exaggerated peripheral extraction or to a combination of these two processes. Furthermore, many studies have described the peripheral glucose extraction during a glucose infusion [8-9], but the peripheral metabolism has not been studied during the first few minutes of a glucose infusion when both glucose and insulin levels rise dramatically. Recently, Rasio et al. have suggested that ansudden change in the arterial concentration of glucose could induce a release from the forearm of insulin which was probably stored on the surface of the capillary endothelium [10] and we have previously described concentration dependent extraction and release of insulin from the heart [11].

Against this background we have studied in the forearm the early arterial and deep venous concentrations of insulin and glucose during a glucose infusion to estimate the early extraction of glucose and insulin in response to a glucose infusion.

\section{Material and Methods}

\section{Subjects}

Four healthy males, aged 22 to 40 years, with a weight/height index ${ }^{1}$ ranging from 0.86 to 1.11 , who had blood lipids and intravenous glucose tolerance within the normal limits $(k$-value $>1.10)$ were studied between 8 and $10 \mathrm{a}$. $\mathrm{m}$. after fasting overnight.

\footnotetext{
1 Weight $(\mathrm{kg}) /($ height $)(\mathrm{cm})-100)$
} 
Table 1. Transit time and maximal a-dv difference and total extractions of insulin and glucose in the four subjects

\begin{tabular}{|c|c|c|c|c|c|c|}
\hline \multirow[b]{2}{*}{$\begin{array}{l}\text { Subject } \\
\text { no }\end{array}$} & \multirow[b]{2}{*}{$\begin{array}{l}\text { Transit } \\
\text { time } \\
\text { sec }\end{array}$} & \multicolumn{2}{|l|}{ Insulin } & \multicolumn{3}{|l|}{ Glucose } \\
\hline & & $\begin{array}{l}\text { Maximal } \\
\mathrm{a}-\mathrm{dv} \text { difference } \\
\mu \mathrm{U} / \mathrm{ml}\end{array}$ & $\begin{array}{l}\text { Total }^{\mathrm{a}} \\
\text { extraction } \\
(\mu \mathrm{U} / \mathrm{ml}) \times \min \end{array}$ & $\begin{array}{l}\text { Maximal } \\
\text { a-dv difference } \\
\mu \mathrm{mol} / \mathrm{l}\end{array}$ & $\begin{array}{l}\text { Total }^{\mathrm{a}} \\
\text { extraction } \\
0 \mathrm{~min}-5 \mathrm{~min} \\
(\mu \mathrm{mol} / \mathrm{l}) \times \min \end{array}$ & $\begin{array}{l}\text { Average } \\
\text { a-dv difference } \\
5 \mathrm{~min}-12 \mathrm{~min} \\
\mu \mathrm{mol} / 1\end{array}$ \\
\hline 1 & 29 & 35 & 67 & 2700 & 7760 & 937 \\
\hline 2 & 18 & 21 & 42 & 3350 & 9895 & 759 \\
\hline 3 & 31 & 30 & 37 & 2050 & 5312 & 618 \\
\hline 4 & 11 & 20 & 52 & 1100 & 3541 & 506 \\
\hline
\end{tabular}

a Area between the arterial and venous concentration curves

\section{Experimental Design}

A teflon catheter was introduced in the distal direction into one of the deep antecubital veins, draining mainly the forearm muscles [12] and another one was put into the brachial artery. An antecubital vein of the other arm was catheterized in the proximal direction for the infusion of glucose. Half an hour later, a bolus of 4 grams of glucose was infused within two minutes in subjects 1,2 and 3 and within 3 min in subject 4 , immediately followed by an infusion of glucose at a rate of $200 \mathrm{mg} / \mathrm{min}$.

Samples were simultaneously taken from the artery and the deep vein at $0 \mathrm{~min}$, before the glucose infusion, and, from $1 \mathrm{~min}$, every $30 \mathrm{sec}$ up to $5 \mathrm{~min}$, then at 8,10 and $12 \mathrm{~min}$, after the start of the glucose infusion. The hand circulation was excluded during sampling by a rubber cuff to prevent admixture of venous blood from superficial tissue. Heparin or saline was not used to keep catheters patent.

\section{Methods}

Blood was collected into plastic syringes, transferred to glass tubes for insulin determination and to heparinised plastic tubes for glucose and haematocrit determinations. Five replicate extracts were prepared immediately for glucose determination [13], which was performed in duplicate on each extract after a few hours. Heparinised blood for haematocrit, which was determined in 4 replicates, and blood, without additions, for insulin analysis were stored till the end of the experiment.

One hour after the sampling, the blood was centrifuged twice and the serum assayed for insulin in 6 replicates, using the double antibody method [14].

During both glucose and insulin analyses manipulations of the arterial and corresponding venous sample were performed in alternation. The average SEM for the glucose determination was $0.70 \%$ and that for insulin $2.0 \%$.

The transit time of the blood across the forearm was measured at the end of each experiment by the bolus injection of Cardio-green and continuous withdrawal of blood from the deep vein through a densitometer (Beckman Instruments). Transit time was defined as the mean of at least 2 determinations, counting the time from the middle of the dye injection in the arterial catheter to the peak of dye concentration registered in the deep vein catheter.

The location in time of the values for the concentration of glucose and insulin in the venous blood have been corrected for each subject with regard to the measured transit time.

\section{Results}

\section{Transit Time and Haematocrit}

The transit time values are given in Table 1 . There was never a significant arterial (a)-deep venous (dv) difference in haematocrit. Mean arterial haematocrit was 43 (range 40-48) and did not change during any study.

\section{Glucose}

Arterial glucose concentration (Fig. 1), 1 min after the beginning of the bolus injection, was already about $50 \%$ higher than the basal value in all subjects and increased continuously up to the end of the bolus, when the maximal arterial level was reached. Thereafter, arterial glucose concentration started to decrease and reached a steady state level (subjects $1,2,4$ ), or continued to fall less steeply (subject 3 ). Deep vein glucose concentration (transit time corrected) increased more slowly and reached a maximum at least $1^{1 / 2} \mathrm{~min}$ after the arterial peak. The a-dv difference increased with rising arterial concentration, reached its maximum at the same time as the arterial level, and then fell to a plateau at about $5 \mathrm{~min}$.

Maximal a-dv difference, total glucose extraction defined as the area of the a-v difference-time curve in the early $5 \mathrm{~min}$ and average a-dv difference during the constant extraction phase are given in Table 1. 

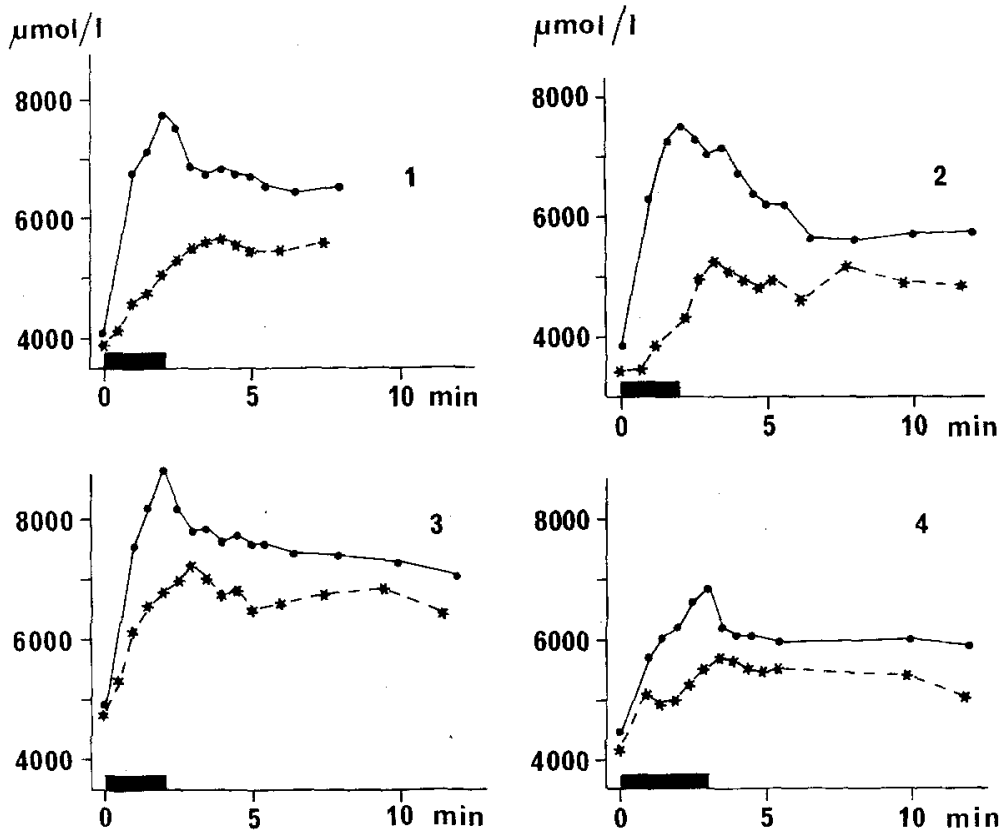

Fig. 1. Concentration of glucose in the four subjects in arterial and deep venous blood. The deep venous concentration values have been corrected according to each subjects transit time. The bar indicates the bolus injection of glucose

$\mu \mathrm{U} / \mathbf{m l}$
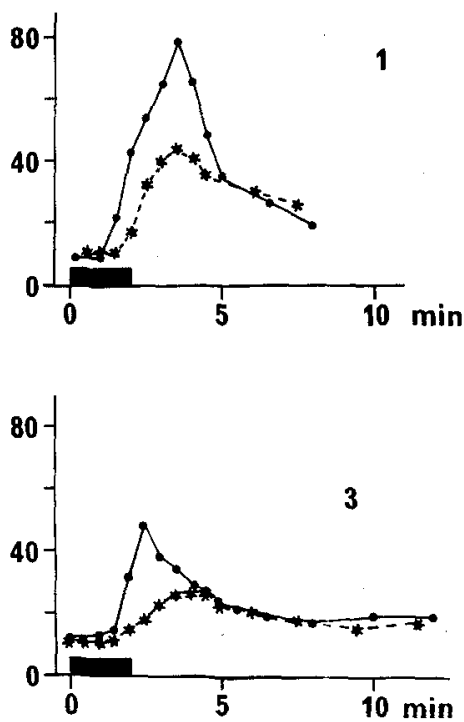

$\mu \mathrm{U} / \mathrm{ml}$
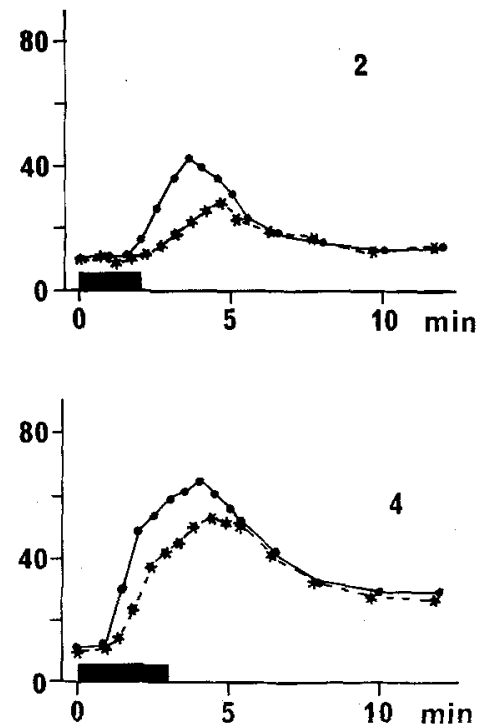

Fig. 2. Concentration of insulin in the four subjects in arterial and deep venous blood. The deep venous concentration values have been corrected according to each subjects transit time. The bar indicates the bolus injection of glucose

\section{Insulin}

The arterial level (Fig. 2) showed, in all subjects, a very distinct peak. Insulin started to rise between $1^{1 / 2}$ min and $2 \mathrm{~min}$ and the maximum arterial concentration was reached between $2^{1 / 2}$ min and $4 \mathrm{~min}$, which was from $30 \mathrm{sec}$ to $1 \frac{1 / 2}{\mathrm{~min}}$ after the arterial glucose peak. After the peak, the arterial insulin level decreased until $10 \mathrm{~min}$, when it reached a plateau in all except subject 1 , in whom sampling was stopped at 8 min before any steady state was achieved in arterial insulin concentration.

The concentration of insulin (transit time corrected) in the deep vein showed a peak which came later than the arterial one in all but one case, and was smaller. The venous peak concentration was only half the arterial peak concentration in two subjects. The venous insulin level had the same value as the arterial from 5 min onwards. This means that there was no longer any net extraction or release of insulin by the forearm up to the end of the experiment. The maximal insulin a-dv difference occurred before the maximal glucose a-dv difference only in subject 4 , while in all the others it took place when the glucose extraction had already started to diminish.

The maximal insulin a-dv differences and the total insulin extractions are given in Table 1. 


\section{Discussions and Conclusions}

Arterial concentrations of glucose and insulin early after the glucose administration, were much higher than those in the deep forearm vein. This is due to an early removal of both glucose and insulin in the forearm muscle vascular bed. Although the extraction occurred in all subjects it differed from subject to subject and did not seem to be directly related to the arterial level. Thus it is possible that subjects with high arterial insulin concentration and great peripheral extraction might appear as low insulin responders, and vice versa, when only venous concentrations of insulin are analysed. These considerations imply that it is not correct to evaluate the early insulin glucose response kinetics (occurring before 5-10 $\mathrm{min}$ ) from measurements of venous insulin concentrations $[15,16]$, as quite erroneous interpretations may result because of the variable and considerable early peripheral insulin extraction.

There was a substantial rise in the extraction of glucose before the insulin uptake by the forearm started to increase. In one subject (no 2) the maximal extraction of glucose $(3350 \mu \mathrm{mol} / 1)$ occurred before there was any extraction of insulin. Furthermore, in all subjects, when the insulin extraction reached its maximum, glucose extraction had already started to decrease. These observations suggest that in the early phase of a glucose infusion the uptake of glucose and insulin by the muscles are almost independent of each other, suggesting that the increased amount of insulin in the receptor sites plays only a minor role in glucose uptake by the muscles under these conditions [8].

In the descending phase of the arterial insulin peak, in all subjects two or more points were found where the measured venous concentration of insulin was significantly higher than the corresponding arterial concentration. However, when, for each subject, the position of the venous curve on the time axis, was corrected by the corresponding transit time value, which was necessitated by the fact that insulin concentration was continuously changing [17], it was no longer possible to find a significant negative arteriovenous difference. Such a negative arterio-venous difference which might result from the release of insulin from the surface of the capillary endothelium, was found by Rasio et al. [10] locally after intraarterial injection of glucose.

We have only found release of insulin from the forearm during forearm exercise (Riccardi et al. unpublished results) although under conditions of steadier levels of arterial insulin concentration we have found a concentration dependent release of insulin from the heart [11].

\section{References}

1. Blackard, W. G., Nelson, N.: Portal vein insulin concentrations in diabetic subjects. Diabetes 20, 286-288 (1971)

2. Simpson, R. G., Benedetti, A., Grodsky, G. M., Karam, J. H., Forsham, P. H.: Early phase of insulin release. Diabetes 17, 684-691 (1968)

3. Turner, R. C., Schneeloch, B., Nabarro, J. D. N.: Biphasic insulin secretory response to intravenous xylitol and glucose in normal, diabetic and obese subjects. J. clin. Endocr. 33, 301-309 (1971)

4. Blohmé, G.: Intravenous glucose tolerance and early insulin response. Acta med. scand., Suppl. 566 (1974)

5. Cerasi, E., Luft, R.: The plasma insulin response to glucose infusion in healthy subjects and in diabetes mellitus. Acta endocr. 55, 278-306 (1967)

6. Lerner, R. L., Porte, D., Jr.: Relationship between intravenous glucose loads, insulin responses, and glucose disappearance rate. J. clin. Endocr. 33, 409-418 (1971)

7. Cerasi, E., Luft, R.: The prediabetic state, its nature and consequences - A look toward the future. Diabetes 21 (Suppl. 2), 685-694 (1972)

8. Dieterle, P., Birkner, B., Gmeiner, K.-H., Wagner, P., Erhardt, F., Henner, J., Dieterle, C.: Release of peripherally stored insulin during acute muscular work in man. Horm. Metab. Res. 5, 316-321 (1973)

9. Daniel, P. M., Love, E. R., Pratt, D. E.: Insulin-stimulated entry of glucose into muscle in vivo as a major factor in the regulation of blood glucose. J. Physiol. 247, 273-288 (1975)

10. Rasio, E., Whichelow, M. J., Butterfield, W. J.H., Hicks, B. H.: Insulin fixation and glucose uptake by forearm tissues in response to infusions of physiological amounts of insulin in nondiabetic subjects. Diabetologia 8, 244-249 (1972)

11. Wahlqvist, M. L., Kaijser, L., Lassers, B. W., Löw, H., Carlson, L. A.: Release of immunoreactive insulin from the human heart. Europ. J. clin. Invest. 2, 407-411 (1972)

12. Coles, D. R., Cooper, K. E., Mottram, R. F., Occleshaw, J. V.: The source of blood samples withdrawn from deep forearm veins via catheters passed upstream from the median cubital vein. J. Physiol. (Lond.) 323, 142-149 (1958)

13. Hjelm, M.: Enzymatic determination of hexoses in blood and urine. Scand. J. clin. Lab. Invest. 18 (Suppl. 192), 85-89 (1966)

14. Hales, C. M., Randle, P. J.: Immunoassay of insulin with insulin-antibody precipitate. Biochem. J. 88, 137-146 (1963)

15. Pelkonen, R., Taskinen, M. R., Nikkilä, E. A.: Early response of plasma insulin to small doses of intravenous glucose: Effect of obesity. J. clin. Endocr. 39, 418-426 (1974)

16. Thorell, J. I., Nosslin, B., Sterky, G.: Estimation of the early insulin response to intravenous glucose injection. J. Lab. clin. Med. 82, 101-110 (1973)

17. Zierler, K. L.: Theory of the use of arteriovenous concentration differences for measuring metabolism in steady and non-steady states. J. clin. Invest. 40, 2111-2125 (1961)

Received: April 6, 1976, and in revised form: July 29, 1976

Prof. L. A. Carlson

King Gustaf V Research Institute

Karolinska Hospital

S-10401 Stockholm

Sweden 